\section{CAUSES AND DIAGNOSIS OF JAUNDICE IN THE ELDERLY}

BY

\section{A. HUETE-ARMIJO,* M.D., B.Sc.}

AND

\section{A. N. EXTON-SMITH, M.A., M.D., M.R.C.P. Whittington Hospital, London}

With a view to establishing the relative incidence of the different causes of jaundice in the elderly all cases treated in the Whittington Hospital during the last three years have been reviewed. The series consists of 80 patients with jaundice admitted to the medical, surgical, and geriatric wards. Their ages ranged from 65 to 89 years, with a mean of 75.7 years.

\section{Type of Jaundice}

The patients have been classified in three main groups (see Chart) according to the nature of their jaundice as assessed at the final diagnosis. The jaundice was obstructive in nature in $80 \%$ of cases, hepatic in $16 \%$, and haemolytic in $4 \%$. For the elderly patients in this series there were almost equal numbers of males and females in the groups whose jaundice was due both to malignant obstruction and to calculi.

The sites of the neoplasm in the 35 patients with malignant obstructive jaundice are shown in Table I. The commonest cause of neoplastic jaundice was carcinoma of the head of the pancreas, followed by secondary carcinoma in the liver in which the primary

\begin{tabular}{|c|c|c|c|c|c|}
\hline Head of pancreas & .. & $\ldots$ & .. & .. & .. \\
\hline Ampulla of Vater & .. & .. & . & .. & . \\
\hline Hepatic duct $\ldots$ & . & $\cdots$ & . & . & . \\
\hline Common bile-duct & . & .. & . & . & * \\
\hline $\begin{array}{l}\text { tall-bladder } \\
\text { iver (cholangioma) }\end{array}$ & $\because$ & 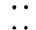 & $\because$ & $\therefore$ & $\ddot{m}$ \\
\hline
\end{tabular}

was in the gastro-intestinal tract in two-thirds of the cases. These figures correspond closely to those given by Schiff (1946). Among the 80 patients were six cases of intrahepatic obstructive jaundice due to drugs: chlorpromazine was responsible in four and phenylbutazone in two.

The type of liver damage in the 13 patients with hepatocellular jaundice is shown in Table II. The ages of the patients with virus hepatitis ranged from 68 to 77 years. The patient with homologous serum hepatitis developed jaundice four months after a blood transfusion for prostatectomy, and in the patient with toxic

TABLE II.-Hepatocellular Jaundice

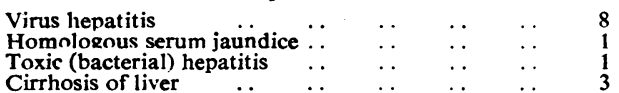

(bacterial) hepatitis the liver damage was secondary to an acute enterocolitis. Haemolytic jaundice is rare in the elderly. There were only three cases in the present series: in one the patient had polycythaemia vera, treated with radioactive phosphorus; in another the haemolysis was due to massive pulmonary embolism in a patient with congestive cardiac failure, and in the third the cause of the haemolysis was unknown.

*British Council Scholar in Geriatrics at Whittington Hospital. Address now 4th C.N.E. No. 203, Managua, Nicaragua (Central America).

\section{Diagnosis of Jaundice}

The causes of jaundice given in the Chart and Tables I and II are based on the final diagnoses in the 80 patients. The method by which the final diagnosis was made is shown in Table III. In 63 cases the diagnosis was confirmed by laparotomy, liver biopsy, or post-mortem examination; in 17 cases the final diagnosis rested on clinical, biochemical, and radiological criteria.

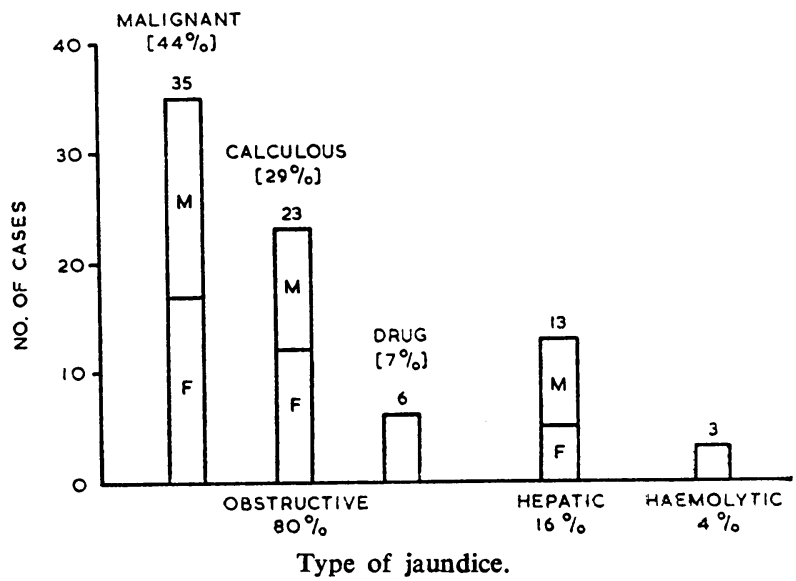

TABLE III.-Method of Determining Final Diagnosis

\begin{tabular}{|c|c|c|c|c|c|c|}
\hline \multirow[b]{2}{*}{ Type of Jaundice } & \multicolumn{4}{|c|}{ Final Diagnosis Determined by } & \multirow[b]{2}{*}{ Total } & \multirow{2}{*}{$\begin{array}{l}\text { Clin- } \\
\text { ical } \\
\text { Diag- } \\
\text { nosis } \\
\text { Correct }\end{array}$} \\
\hline & $\begin{array}{c}\text { Opera- } \\
\text { tion }\end{array}$ & P.M. & $\begin{array}{l}\text { Liver } \\
\text { Biopsy }\end{array}$ & $\begin{array}{c}\text { Clinical } \\
\text { Exam- } \\
\text { ination* }\end{array}$ & & \\
\hline $\begin{array}{l}\text { Malignant obstruction } \\
\text { Calculous obstruction } \\
\text { Drug toxicity } \\
\text { Hepatocellular } \\
\text { Haemolytic .. . . }\end{array}$ & $\frac{10}{4}$ & $\begin{array}{r}25 \\
\frac{2}{5} \\
1\end{array}$ & $\frac{z}{3}$ & $\begin{array}{l}-8 \\
6 \\
1 \\
2\end{array}$ & $\begin{array}{r}35 \\
23 \\
6 \\
13 \\
3\end{array}$ & $\begin{array}{r}33 \\
23 \\
6 \\
7 \\
3\end{array}$ \\
\hline & 27 & 33 & 3 & 17 & 80 & 72 \\
\hline
\end{tabular}

* Supported by biochemical and/or radiological evidence.

\section{Obstructive Jaundice}

Neoplastic Obstruction.-The correct diagnosis of neoplastic obstruction was made clinically in all but 2 of the 35 cases. One patient was thought to have acute hepatic failure, but post-mortem examination revealed a primary carcinoma of the stomach with metastases in the liver; in another patient the diagnosis of cirrhosis was made (largely on the basis of impaired liver-function tests-a thymol turbidity of 7 units and a S.G.P.T. of 300 units), but the correct diagnosis proved to be a hypernephroma with liver metastases.

Calculous Obstruction.-In all 23 patients with calculous jaundice it is believed that the clinical diagnosis was correct. It is worthy of mention, however, that, although the jaundice was either recurrent or varying in intensity, only seven patients had biliary colic and six had signs of cholecystitis.

Intrahepatic Obstruction Due to Drugs.-In all six cases when the history of administration of chlorpromazine or phenylbutazone was obtained there was no great difficulty in making the clinical diagnosis of intrahepatic obstruction. In each case the thymol turbidity was normal, the alkaline phosphatase was raised (between 35 and 99 K.A. units in five cases, and just above normal, 18.2 units, in one case), and the jaundice cleared rapidly when the drug was discontinued.

\section{Hepatocellular Jaundice}

It was in this group that most errors in diagnosis occurred. In no fewer than 5 out of the 13 patients 
whose final diagnosis was hepato-cellular jaundice diagnosis of obstruction had been made clinically, and four of these patients were submitted to laparotomy (fortunately without ill effects attributable to the operation). The true nature of the illnesses in these patients, confirmed by biopsy or post-mortem examination, was virus hepatitis in all cases. On review, in two patients submitted to laparotomy the operation might have been avoided, since the biochemical findings showed evidence of liver damage. On the other hand, three of the eight patients with virus hepatitis showed no indication of hepatocellular damage, as their thymol turbidity tests (and in two their transaminase levels) were within normal limits; the serum alkaline phosphatase levels also were only slightly raised (14 to 26 units). The atypical hepatitis in these patients is the variety which has been called cholangiolitic hepatitis or hepatitis with intrahepatic cholestasis.

\section{Haemolytic Jaundice}

There was no difficulty in determining the type of jaundice on the basis of the clinical and biochemical findings in the three patients in this group.

\section{Discussion}

The high incidence $(73 \%)$ of extrahepatic obstructive jaundice in this series of older patients may be compared with the incidence in patients belonging to younger agegroups. In a series of 575 patients aged 14 and over Schiff (1946) found the jaundice to be of the hepatic type in $65 \%$, neoplastic in $.21 \%$ and calculous in $6 \%$ of cases. The almost equal sex incidence in the groups whose jaundice was due both to malignant obstruction and to calculi in the present series is also of interest. At younger ages neoplastic jaundice is more common in men $(72 \%)$ than in women $(21 \%)$, according to Cayer (1960). Calculous jaundice in middle age is much more common in women than in men; the ratio is reported as ranging from $3: 2$ (Trueman, 1940) to $9: 1$ (Cutler and Zollinger, 1940).

There was no great difficulty in making the diagnosis in the group of patients with obstructive jaundice. The absence of pain in the patients with obstruction due to gall-stones must be remembered; only 7 of the 23 patients had biliary colic. Schiff (1956) states that he " has been impressed with the frequency of painless jaundice in elderly individuals suffering with common duct stone." It is essential in every jaundiced patient to make a specific inquiry about the administration of drugs which are apt to cause intrahepatic cholestasis. Chlorpromazine and phenylbutazone are often responsible, since they are commonly used in the elderly, but the possible toxic effects of methyltestosterone, norethandrolone, thiouracil, sulphonamides, and the arsenicals should be borne in mind.

Cirrhosis and hepatitis have their maximum incidence in younger patients, and in the present series in only $16 \%$ was the jaundice due to hepatocellular damage. But it is here in this comparatively small group that most of the difficulties in making a differential diagnosis of jaundice arise. Particular attention must be paid to the atypical forms of hepatitis in which features of intrahepatic cholestasis predominate over the inflammatory changes. The aetiological agent is believed to be a variant of the virus of infective hepatitis (Dubin et al., 1959). The difficulty in assessment of these patients rests not only on the interpretation of the clinical and biochemical findings but even on the biopsy material as well (Weisbrod et al., 1950). Among their 28 patients with jaundice due to virus hepatitis, all of whom had an aspiration biopsy of the liver, Shorter et al. (1959) found five cases of intrahepatic cholestasis ; four of the five were submitted to laparotomy because of lack of confidence in the diagnosis made by needle biopsy. Sborov and Keller (1951) emphasize the fact that some patients may require exploration to establish the diagnosis.

In the present series the correct clinical diagnosis, supported by biochemical and radiological evidence, was made in $72(90 \%)$ of the 80 patients with jaundice. This figure corresponds fairly closely with that given by Cayer (1960), who found that the correct diagnosis can be ascertained pre-operatively in $85 \%$ of jaundiced patients.

\section{Summary and Conclusions}

In a series of 80 patients whose ages ranged from 65 to 89 years the jaundice was obstructive in nature in $80 \%$. The obstruction was due to malignancy in $44 \%$, to calculi in $29 \%$, and to the toxic effects of drugs in $7 \%$. Hepatocellular damage is relatively less common in the elderly and accounted for $16 \%$ of the cases, and haemolytic jaundice is rare (4\% of cases).

In contradistinction to jaundice in the younger agegroups almost equal proportions of men and women in the present series had malignant obstruction ; moreover, a similar equality of sex incidence was found in calculous jaundice.

It is believed that the correct clinical diagnosis, supported by the biochemical and radiological findings, was made in $90 \%$ of cases. Most errors occurred in the hepatocellular group, where an incorrect clinical diagnosis of obstructive jaundice was made in five patients. The chief cause for error is the occurrence of atypical forms of hepatitis in which features of obstruction due to intrahepatic cholestasis predominate. Moreover, error cannot always be avoided by liver biopsy owing to difficulty in interpretation of histological material in some instances.

In order to avoid overlooking other causes of intrahepatic cholestasis careful inquiry about the administration of drugs must be made in all patients with jaundice. Chlorpromazine is most often responsible in the elderly.

We thank Drs. M. G. Ashby, A. Bloom, A. L. Jacobs. T. St. M. Norris, and H. E. S. Pearson, and Messrs. J. M. Davis, P. T. Savage, and N. E. Stidolph for allowing us to include in this series patients under their care.

\section{REFERENCES}

Cayer, D. (1960). In The Older Patient, p. 354, edited by W. M. Johnson. Hoeber, New York.

Cutler, E. C., and Zollinger, R. (1940). Amer. J. Surg., 47, 185

Dubin, I. N., Sullivan, B. H., LeGolvan P. C., and Murphy, L. C. (1959). In Proceedings of World Congress of Gastroenterology, 1958, p. 888. Williams and Wilkins, Baltimore Sborov, V. M., and Keller, T. C. (1951). Gastroenterology, 424.

Schiff, L. (1946). The Differential Diagnosis of Jaundice, p. 26 Year Book Publ., Chicago.

(1956). Diseases of the Liver, p. 187. Pitman, London.

horter, R. G., Paton, A., and Pinniger, J. L. (1959). Quart. J. Med., 28, 43 .

Trueman, K. R. (1940). Proc. Mayo Clin., 15, 283.

Weisbrod, F. Y., Schiff, L., Gall, E. A., Cleveland, F. P., and Berman, J. R. (1950). Gastroenterology, 14, 56.

The new $£ 72,000$ Oppenheimer College in Lusaka started its first training course in social work last December. Eight of the first 25 students are women. There are five Europeans, two Eurasians, and the rest are Africans. 